\title{
Investigating Paragraph Writing Skills among Polytechnic Students: The Case of Kumasi Polytechnic
}

\author{
Kwasi Sarfo-Adu \\ Department of Liberal Studies, Kumasi Polytechnic, Kumasi, Ghana
}

Email address:

k.sarfoadu@yahoo.com

To cite this article:

Kwasi Sarfo-Adu. Investigating Paragraph Writing Skills among Polytechnic Students: The Case of Kumasi Polytechnic. International Journal of Language and Linguistics. Vol. 3, No. 3, 2015, pp. 145-153. doi: 10.11648/j.ijl1.20150303.16

\begin{abstract}
Paragraphs are the building blocks of essays. A sound knowledge of paragraph structuring leads to well-written and readable essays. On the contrary, a lack of paragraph writing skills culminates into a farrago of ideas scattered haphazardly in the essay, thereby affecting paragraph unity and coherence, which in turn impacts negatively on the packaging of ideas in the essay. This study has been prompted by my observation over the years of paragraph construction difficulties polytechnic students face in their academic writing, and also the paucity of research in polytechnic writing. As a result, this paper set to investigate how students structure their paragraphs in terms of topic sentence use and support sentences. A corpus of 120 essays was collected from four departments in Kumasi Polytechnic, Kumasi, Ghana and using Bain's paragraph principles as a benchmark to analyse them, the results revealed that $66 \%$ of the essays employed definite paragraph format. The study also found numerous one-sentence paragraphs leading to the creation of indentations, with reckless abandon. The results of the study have implications for the teaching of writing skills in polytechnics.
\end{abstract}

Keywords: Paragraph, Topic Sentence, Support Sentence, Indentation, Controlling Idea

\section{Introduction}

Researchers in tertiary student writing seem to have an inordinate likeness for students at the universities to the neglect of polytechnic students (see Afful 2005, Bunton 2005 Anyidoho 2002,Adika 1999, Ballard and Clanchy 1998, Chan 1994). This has resulted in a yawning gap in academic studies about the writing of polytechnic students. However, it is gratifying to know that some attention is now being given to English in the polytechnics. Studies like Abubakar (2014), Li (2012) and Santhi (2011) address polytechnic English from different perspectives. While Li (2012) reports of a breakthrough in workplace English in Handon Polytechnic in China and advocates workplace English for polytechnics, Abubakar (2014) examines the challenges of teaching English in Nigerian polytechnics just as Santhi (2011) discusses problems of teaching English at the polytechnic level in India and suggesting techniques for handling mixed ability classes for effective teaching and learning of English. The current paper as well explores polytechnic English but focuses particularly on paragraph development.

In going about their academic work, polytechnic students like any other tertiary students write academic essays in which they employ paragraph skills to put their thoughts together to compose the essays. An essay with jumbled ideas strewn in the various paragraphs affects readability; thereby putting the reader off, and also giving a bad impression about the writer. The ability to write with skill and finesse is an asset that every tertiary student must strive to have. This demand made on them by academic writing cannot be compromised. This is because it is incumbent on every writer to package the different pieces of information into wellorganized paragraphs for the write-up to be readable. Anything contrary will affect readability because readers may not know and understand how sub-ideas derived from the thesis of the essay have been partitioned. This calls for a sound knowledge in the construction of paragraphs in essays.

\subsection{The Paragraph Defined}

The paragraph has been defined variously by different writers since there is no universally accepted definition. For lack of space, only few of the definitions are captured here. As far back as 1862, Angus in his book Handbook of the English Tongue defined the paragraph as:

A combination of sentences, intended to explain, illustrate, or prove, or applysometruth; or to give a history of events 
during any definite portion of time, or relation to any one subject of thought.(p. 401, qtd. by Duncan, 2007: 111).

Similarly, Bain in his 1866 edition of English Composition and Rhetoric described the paragraph as the next division of discourse beyond the sentence and defined it as "a collection of sentences with unity of purpose" (p. 142, qtd. by Duncan 2007:112). The paragraph is also defined as "a physical division of a composition, marking a stage in a writer's thought" (Warriner, 1982: 259). On his part, Njoku (1997:209) defines a paragraph as "the largest single unit of an essay. It develops one single, main idea by means of supporting facts." Webster's Universal Dictionary and Thesaurus (2003: 350) also defines the paragraph as "a subdivision in a piece of writing used to separate ideas, marked by the beginning of a new line." A closer look at the various definitions reveals that they all speak to the fact that a paragraph is a group of sentences that speak to a single idea. Therefore a working definition of the paragraph for this paper, derived from the various definitions, is "a group of related sentences that discuss one main idea, the first sentence of which begins on a new line."

A motivation for this paper stems from the paucity of research in polytechnic writing. It is to bridge this gap that this study is carried out to investigate paragraph skills of polytechnic students as they go about writing their academic essays. The basic question the study hopes to answer is: What is the extent of knowledge of paragraph structure among polytechnic students?

\subsection{Paragraph Theory}

Since the publication of Joseph Angu's The Handbook of the English Tongue (1862), which provided twenty pages of paragraphing tips, and Alexander Bain's English Composition and Rhetoric, which set forth formal principles for paragraph composition, two views of paragraph writing have existed: the prescriptive and the descriptive schools (Duncan, 2007).The prescriptive school is rooted in Bain's ideas. Bain is acknowledged to be the first to provide a systematic description of paragraph theory (Shearer 2009, Smith 2008, Duncan 2007, D’Angelo 1986). Bain advocated that the paragraph must have an ideal structure that is measurable and describable and went on to postulate six principles to govern the creation of a paragraph. The six principles as stated by Lewis $(1894,2006)$, are summarized below.

i. The beginning of each sentence upon what precedes shall be explicit and unmistakable

ii. When several consecutive sentences iterate or illustrate the same idea, they should, so far as possible be formed alike. This may be called the rule of parallel construction.

iii. The opening sentence, unless so constructed as to be obliviously preparatory is expected to indicate with prominence the subject of the paragraph.

iv. A paragraph should be consecutive or free from dislocation.

v. A paragraph should possess unity; which implies a definite purpose and forbids digression and irrelevance.

vi. As in the sentence, so in the paragraph a due proportion should obtain between principal and subordinate statements.

All that these mean is that the paragraph must have an opening sentence embodying the subject matter, and all other sentences should converge on the opening sentence to achieve unity.

According to Lewis, these six principles were illustrated and defended with acuteness and vehemence and grasp that have made Bain perhaps the ablest writer on rhetoric since Aristotle. Bain's prescription, even though somehow rigid, "is so inexorably ingrained into all textbooks and thought that even today it seems that the last 140 years have just been an extremely long field test for his theories" ( Duncan 2007: 110).

The descriptive school of paragraph thought, on the other hand, is associated with Angus (1862) whose ideas "are the antitheses of those of the better-known father of paragraph theory, Alexander Bain" (p.112). This school of thought, according to Duncan (2007), draws on empirical studies to show that a considerable amount of non-textbook structures make little use of the topic sentence "as support for a looser, inductive approach to instruction, with Bain-style rules limited to suggesting a structural ideal that is only rarely seen" (p.109). Duncan (2007) states that Scott and Denney (1893), favouring the descriptive school, were the first in a series of blows against Bain's prescriptive approach although they acknowledged his influence, particularly his analogy of sentences and paragraphs. They suggested that the paragraph be placed at the centre of instruction through nonstructural reasons, a concept which was then new. Scott and Denney stressed that as the paragraph is analogous to the essay, it makes room for more rewriting and practice in limited time. Again, a rather vociferous branch of the descriptive school, the functionalists, extending the argument further claimed that Bain's model ruthlessly locked students into a "deductive cage" (Rodgers, 1965:408).

Notwithstanding the series of attacks against the Banish tradition, its basic principles unquestionably hold sway as a lot of textbook writers fall on them in the construction of paragraphs (Duncan 2007). Bain's six rules “have indeed had a very strong influence in leading the teachers of paragraph principles to advocate a purely logical structure...." (Lewis 2006, p. 125).Bain's paragraph principles are simple for any average tertiary student to follow; hence, in the current paper, his paragraph development prescription is adopted as the benchmark to answer the question What is the extent of knowledge of paragraph structure among polytechnic students?

\section{Related Literature}

Paragraph studies (Rasheed et al. 2013, Shearer 2009, Shaojun 2008, Smith 2008, Duncan 2007, Sporleder \& Lapata 2004, Wilson 1998, Stark 1988, D’Angelo 1986, Bond \& Hayes 1984, Hinds 1977) tend to focus essentially on methods of constructing a paragraph. This is perhaps 
attributable to prescriptions by textbook writers of the $19^{\text {th }}$ century, who suggested that the main idea of a paragraph should be embodied in the topic sentence. The writer should then develop the central idea in the topic sentence into a unified and coherent paragraph (D'Angelo, 1986). This idea of a definite format of the paragraph was the legacy of the prescriptive school paragraph thought championed by Alexander Bain in the $19^{\text {th }}$ century.

Echoing Bain's principles, Rasheed et al. (2013) in their paper Paragraph Inner Structure: The Step Model looks at the paragraph as consisting of two important parts: a topic sentence that expresses the main thrust of the paragraph and the accompanying sentences that explain or account for the topic sentence. They call the accompanying sentences explaining sentences, and the complexity of the topic sentence determines the number of explaining sentences in the paragraph. According to them, in the Step Model, each step represents one level of maturity and the topic sentence is the first step towards the maturity of the idea. It is only from the topic sentence that a reader can cross over to the second step which is the first explaining sentence and so on. They also talk of the "Topic Sentence Heaviness" which is related to the step model in that the most important idea can be found in the heaviest step. Rasheed et al. opine that we can measure the scale of heaviness according to the number of sentences in one paragraph. For instance, if the heaviness of a topic sentence is "4 degrees" (every sentence equals one degree), it means that we need four steps to go upward. The next is the 1st explaining sentence which will have a heaviness of " 3 degrees" followed by the $2^{\text {nd }}$ explaining sentence whose heaviness will be " 2 degrees" and so on. The lightest step in this model is the $4^{\text {th }}$ explaining sentence owing to the fact that there are no more steps to go upward. Below is a pictorial representation of the Step Model.

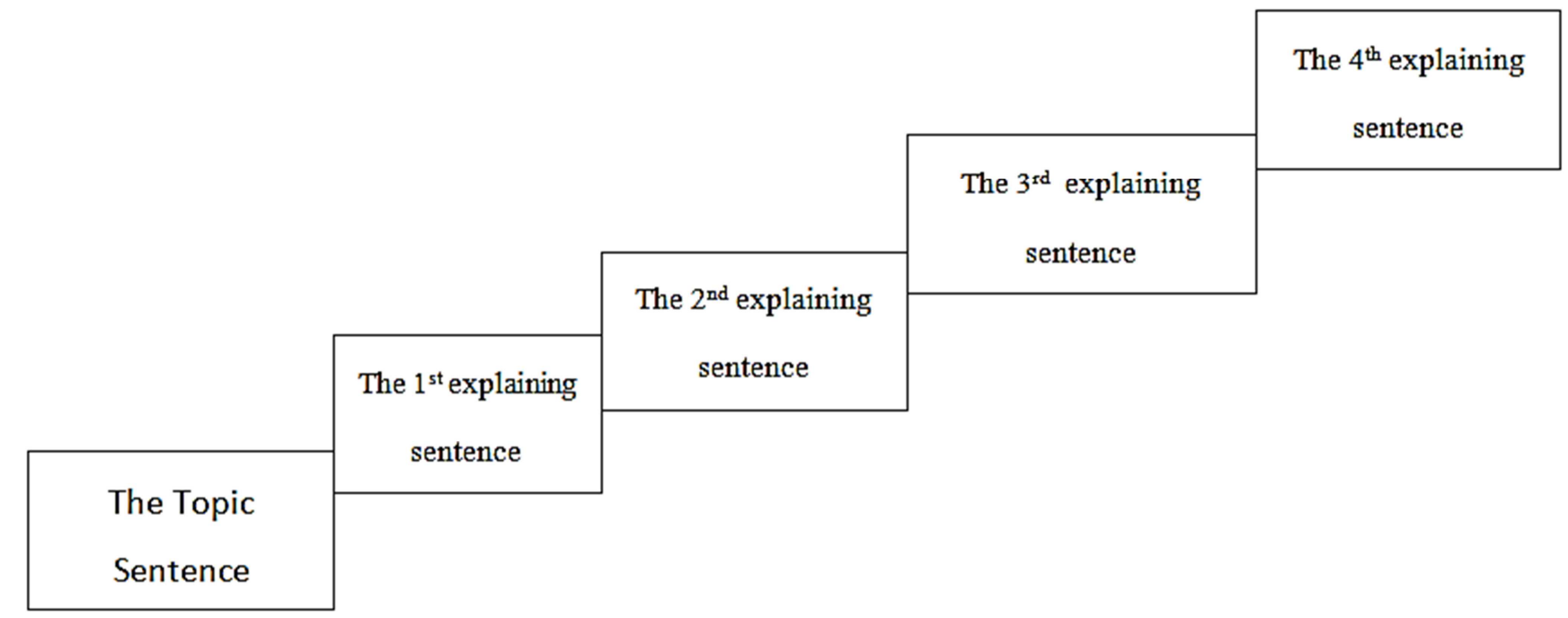

Source: Rasheed et al. (2013)

Figure 1. The Step Model.

According to the model, the importance of any explaining sentence is contingent on how it is close to the topic sentence. Thus speaking emphatically, the $1^{\text {st }}$ explaining sentence is more important than the $2^{\text {nd }}$ explaining, in that order. Rasheed et al. argue that "the power the topic sentence exercises on the explaining sentences in one paragraph starts to fade out as the explaining sentence falls far from its firm grip" (p. 167).

The step model is a bold attempt to formalize paragraph structuring in order that every explaining sentence could speak to the topic sentence, to bring unity and coherence. However, it cannot be applicable to all paragraphs, as some paragraphs have their topic sentences placed in the middle or at the end. Besides, the claim that the farther a sentence is away from the topic sentence makes it less or least important is farfetched and contentious. This is because there are nontopic sentence paragraphs (Braddock 1974) and one-sentence paragraphs (Bowman, 2009).

\subsection{Simple and Complex Topic Sentences}

The topic sentence could be simple or complex. According to Juzwiak (2009) the topic sentence may identify the support points in addition to the topic just as Gogovi et al. (2004) and Sekyi-Baidoo (2003) assert that there are simple and complex topic sentences. According to them, the simple topic sentence or the basic topic sentence as Juzwiak (2009) calls it merely states the topic of the paragraph without stating the sub-ideas, which will form the details of the controlling idea, as exemplified in the following: A major problem confronting the new nation is leadership (Sekyi-Baidoo, 2003: 159) or I could not live without my car (Juzwiak, 2009: 52). In contrast, the complex topic sentence states the controlling idea together with its sub-ideas as in, $A$ major problem confronting the new nation is leadership, which manifests as traditionalor the modern (.Sekyi-Baidoo, 2003:159) or I could not live without my car, a beat-up 1992 Honda Civic (Juzwiak, 2009: 52).

The simple or basic topic sentence is a bit "open-ended" 
which may give room for an inexperienced writer to write anything he/she can think of the topic, which in the end might affect the unity and coherence of the paragraph. The complex topic sentence is also not without its setbacks. The novice writer might be tempted to develop the sub- ideas or support points into separate paragraphs instead of one paragraph with sub-ideas or support points. Nonetheless, the complex topic sentence gives the reader the opportunity, from the very beginning, to know what the writer is going to say about the topic. It also guides the writer to select only details that are related to the topic. Any idea that does not address the topic of the paragraph is extraneous; hence it breaks paragraph unity.

The seemingly overreliance of the topic sentence in paragraph construction has met with some criticisms. Scott and Denney (1893) in their rejection of Bain's paragraph principles, kicked against the topic sentence being subjected to rigid and ironclad positional constraints, and asserted instead that the topic sentence should be allowed to be mobile, not just in the first position. Similarly, Martin and Ohmann (cited by D'Angelo 1986:433) rubbish the importance of the topic sentence thus:

The topic sentence is a more or less fictitious entity

The topic sentence is something a reader extracts from a paragraph and something a writer has in mind as the unity he wants to achieve.

The schoolboy notion of a topic sentence as the big firecracker, from which a string of little firecrackers is ignited, has little relationship to the truth (p.207).

The quotation above downplays the value of a topic sentence by suggesting that it is the reader who extracts it from the paragraph in as much as the writer has in mind to use it to achieve unity. This kind of reasoning is rather spurious just as it is contradictory in that in one breadth Martin and Ohmann acknowledge the topic sentence but in another breadth they trivialize it as "a schoolboy notion." Contrary to their claim, much academic writing employs the topic sentence to signal paragraph topic. What is more, if we want to produce skilful readers, then it is imperative that we teach readers to find main ideas at the beginning of the paragraph because that is where they are frequently located (Smith, 2008).

Perhaps, a study by Braddock (1974) has been the most influential of the non-topic sentence school of thought. In a study to find out how professional writers employ topic sentences, Braddock found out that only $13 \%$ of expository paragraphs began with topic sentences. He therefore concluded that expository writing rarely began with topic sentences, and enjoined teachers to refrain from presenting the topic sentence as sacrosanct and indispensable in paragraph construction. Braddock's study has been cited extensively to back his call for teachers to reconsider how they teach reading and writing (Smith 2008). Without contesting Braddock's findings, we can equally argue that his corpus of 25 essays is not representative enough to warrant such a rather audacious overgeneralization. Braddock's conclusions prompted Popken (1987) to conduct a similar study to "set the records straight" on topic sentence use in written discourse. His study, as cited by Smith (2008), revealed that a good number of paragraphs $(78 \%$ across disciplines) are directly or indirectly influenced by either a major or minor topic sentence. According to Smith, Popken pointed out that "Braddock's homogenous corpus had been widely over generalized to be indicative of written discourse" (p. 79). Accordingly, Popken called for a reassessment of conclusions made by Braddock.

In another study by Smith (2008) to determine whether Braddock's conclusions about the topic sentence are valid or whether Popken's clarion call for a re-examination of Braddock's conclusions is in order, he found out that two thirds of the cases made use of topic sentences, which were also placed at the beginning of the paragraphs. Consequently, Smith calls for a reassessment of Braddock's view about topic sentence usage in academic writing while at the same time endorsing Popken's advocacy for a re-examination of Braddock's posturing about the topic sentence in academic writing. This paper is equally in support of the position adopted by Smith and Popken on the grounds that the topic sentence cannot be wished away in teaching paragraph writing, especially in ESL or EFL situations.

Similarly, Appiah (2002), and reported by Afful (2005) examined paragraph development in essays of first-year students of University of Cape Coast, Ghana and found problems of intrusion of new ideas not captured in the topic sentence, topic shifts and paragraph fragments. These findings suggest that the students lacked paragraph skills as they did not follow paragraph development prescriptions of Bain or textbook writers.

\subsection{Paragraph Length}

An equally important aspect of paragraph writing, in relation to the essay, is paragraph length. There is no hard and fast rule about how long a paragraph should be. The length of a paragraph is dependent on the topic idea being discussed. On how long a paragraph should be, Nichol (2008) writes:

And dictating that a paragraph consists of a given number of sentences is understandable but lazy approach that ensures that student writers provide details before moving on to the next idea but does not teach them why they must hit the number - much like requiring a word count for an essay or report ensures that most students will focus on grasping for quantity rather than striving for quality (www.dailywritingtips.com/).

Nichol couldn't have said it any better. Legislating that a paragraph should be this or that long will make student writers put a premium on the number of sentences rather than on the quality in terms of paragraph structure, unity, coherence and adequate development.

On his part Bowman (2009) suggests that the complexity of the controlling idea and the reader's need for explanation determine the length of the paragraph. If this is so, then how do we account for one-sentence paragraphs, some of which are very short? Opinions are divided on one-sentence 
paragraphs in academic writing. Edwin (2006) quotes Earle as suggesting that "the term paragraph can hardly be applied to anything short of three sentences." This quote is nothing but an indirect rejection of one- sentence paragraphs. But Alred (2012) thinks otherwise when he argues that occasionally, one can use the one-sentence paragraph as a transition between longer paragraphs or introductions or conclusions in correspondence. Similarly, Bowman (2009) does not kick against one-sentence paragraphs. He even goes ahead to provide three guidelines for using one-sentence paragraphs: 1. Use them for stand-alone ideas that do not need explanations 2. Use them when you want to create heavy emphasis for an idea, and 3. Use them infrequently. The third point is worthy of particular attention because a write-up that is replete with one-sentence paragraphs is boring and shows the writer's lack of depth in details or support ideas. It is no wonder why Lee (1998) thinks that "a one-sentence paragraph can sound too brisk and implies a lack of penetration and analysis". However, an examination of quotations, dialogue and journalistic writing shows preponderance for one-sentence paragraphs.

\subsection{Paragraph Boundaries}

Regardless of the length, a new paragraph is signaled by what is technically called indentation (Brown \& Yule 1986) paragraph boundary (Grimes 1975, Stark 1988). Without the indentations or the boundaries it will be difficult for readers to identify topic shifts in essays. Grimes (1975) considers the delineation of paragraph boundaries as one form of "partitioning" in discourse. According to him, we can partition paragraphs based on change of setting (time and place), and theme (the person or thing being discussed in a narrative discourse).

Paragraph boundary detection has been studied by a number of scholars including Shaojun (2008), Sporleder and Lapata (2004), Stark (1988), Bond and Hayes (1984). For example, in Stark's study, respondents were asked to indicate paragraph boundaries in fiction texts where paragraphs boundaries had been removed. Results indicated that they were able to indicate the boundaries with accuracy. In addition, paragraph length varied from subject to subject based on what ideas they considered to be important. Similarly, Sporleder and Lapata used a machine learning approach to investigate whether paragraphs could be identified automatically across different languages and domains. The results indicated that humans achieved accuracies ranging between $77.45 \%$ and $88.58 \%$ where some domains were less difficult than others. Again, their models achieved accuracies of within $6 \%$ of human performance. These studies point to the fact that paragraph detection is, in large measure, based on how writers package information in their paragraphs. The present study focuses on polytechnic students' paragraph structuring skills, in terms of creating a topic sentence and developing it with support sentences.

\section{Methods}

The purpose of the study is to investigate the depth of paragraph writing skills among polytechnic students; particularly how they structure their paragraphs and how they are able to develop the controlling idea through topic sentences with accompanying supporting sentences. The study area is Kumasi Polytechnic, one of the 10 polytechnics in Ghana offering 3-Year Higher National Diploma (HND) programmes. The population for the study is HND students of the Faculty of Business, comprising 4 departments; namely, Accountancy Management Studies, Purchasing \& Supply and Marketing. The Faculty of Business is selected in that in comparison with other faculties such as Engineering and Applied Science, the Faculty of Business has an essay component of their end- of- semester examination questions as opposed to calculation questions by the other faculties. Again, it was thought that conclusions about paragraph creation could be best drawn from continuous writing or essays. Sixty examination scripts, with 20 from each year group, were randomly selected from each of the departments bringing the total number up to 240 scripts. Then using purposive sampling 30 scripts were picked from each department making a total of 120 essays for analysis. Table 1 displays a summary of the data.

Table 1. Distribution of Essays across Departments and Year Groups.

\begin{tabular}{lllll}
\hline Department & Year1 & Year 2 & Year 3 & Total \\
\hline Accountancy & 10 & 10 & 10 & 30 \\
Management & 10 & 10 & 10 & 30 \\
Marketing & 10 & 10 & 10 & 30 \\
Purchasing & 10 & 10 & 10 & 30 \\
Total & 40 & 40 & 40 & 120 \\
\hline
\end{tabular}

\section{Procedure}

After the essays were selected, each of them was carefully read to identify topic sentences, following Smith's (2008) Discourse Block Analysis in identification of topic sentences. According to Smith, to identify a discourse block each essay is carefully read to pick the thesis statement. Then each essay is read again and the main points supporting the thesis are identified. Each of these main points constitutes the topic idea of a discourse block. Aside from the "main points" discourse blocks also called body blocks, the introductory and concluding blocks of each essay are also identified. In this way, "discourse blocks can be determined and discourse block topic sentences, sentences within a particular discourse block which express the main idea of the whole block are located" (p.82). It is worthy of note that a discourse block may span more than one paragraph, depending of the main point being discussed. A slight departure from Smith's discourse block analysis is that instead of deriving the main points from the thesis statement and using them to identify topic sentences and decide a discourse block, the present study used indentations or paragraph boundaries for paragraph identification. This was because most of the essays 
did not contain thesis statements, either explicit or implied.

Then the essays were coded for easy identification, using letters and year group of subjects' departments. Thus the first essay from Accountancy Department, Year One was labeled "Acc Y1.1" second essay Acc Y1.2 etc; Department of Management Studies, "Mgt. Y 1.1" ; Department of Marketing, "Mkt. Y 1.1" ; Department of Purchasing and Supply; "Pur Y 1.1". etc. Next, the essays were read carefully for paragraph selection. Only paragraphs with wellstructured format (topic sentences and support sentences) that conformed to the Bainish paragraph principles were selected for analysis. By implication one-sentence paragraphs were not chosen for study. Again, only body paragraphs were chosen for analysis as most of the essays had one-sentence introductory or concluding paragraphs.

After a paragraph had been chosen, the sentences in the paragraph were numbered for easy identification as a topic sentence or support sentences. For the analysis, the support sentences were categorized into major support and minor support in line with Gogovi et al. (2004), Pardede (2012), Sekyi-Baidoo (2003). These writers explain that the major support sentence speaks directly to the topic sentence whereas the minor support sentence explains the idea in the major support sentence by way of illustrations, examples, statistics, anecdotes and the like. Thus while the relationship between the major support sentence and the topic sentence is direct that between the minor support sentence and the topic sentence is indirect. A paragraph may have more than one major support sentence and several minor support sentences. This categorization of the support sentences into major and minor support sentences helps in the identification of the functional role of each support sentence in the paragraph.

\section{Analysis and Discussion}

The analysis employed the mixed method: quantitative and qualitative. The quantitative approach was used to analyse the data in terms of percentages and absolute figures and presented in a histogram. This was followed by a qualitative analysis of the findings. Table 2 below presents results across the departments and year groups.

Table 2. Essays with well-structured paragraphs across departments and year groups.

\begin{tabular}{lllll}
\hline Department & Year 1 & Year 2 & Year 3 & Total \\
\hline Accountancy & 4 & 7 & 6 & 17 \\
Management & 6 & 6 & 8 & 20 \\
Marketing & 7 & 7 & 8 & 22 \\
Purchasing & 5 & 8 & 7 & 20 \\
Total & 22 & 28 & 29 & 79 \\
\hline
\end{tabular}

Table 2 shows that Accountancy had 17 (56.6\%) essays with well-structured paragraphs while Management Studies and Purchasing had $20(66.6 \%)$ each with Marketing recording the highest of $22(73.3 \%)$. Again, in terms of year groups, out of the 40 essays for each group, Year 3 had 29
(72.5\%) followed by Year 2, $28(70 \%)$ and Year 1, $22(55 \%)$ in that order. Overall out of the120 essays that were analyzed, 79 essays representing $66 \%$ were found to have employed a definite format, i.e. topic sentence followed by support sentences. Based on the results, it could be concluded that students of Kumasi Polytechnic have a fair knowledge of paragraph structure. This conclusion answers the main research question, What is the extent of knowledge of paragraph structure among polytechnic students?

The relatively low rating of Accountancy may be due to the fact that their programme involves much more calculation than the other departments. The implication here is that the accountancy student deals more with figures and calculation than continuous writing (a chat with HOD of Department of Accountancy). If any writing is done at all, it may involve explanation of accounting terminologies which may require one or two sentences, and that may not pass the test of paragraph construction.

The year group standings do not come as a surprise because all things being equal, we expect students in Year 3 to have better paragraph writing skills than their counterparts in Year 2 and Year 1 while those in Year 2 are expected to do better than their colleagues in Year 1. This is because of the number of years each group have been exposed to or engaged in academic writing. We do not expect a first year student to have better writing skills than a third or final year student. Situations like that do happen, but they are isolated cases. This does not mean that the results were skewed in favour of Year 3 students to meet our expectations.

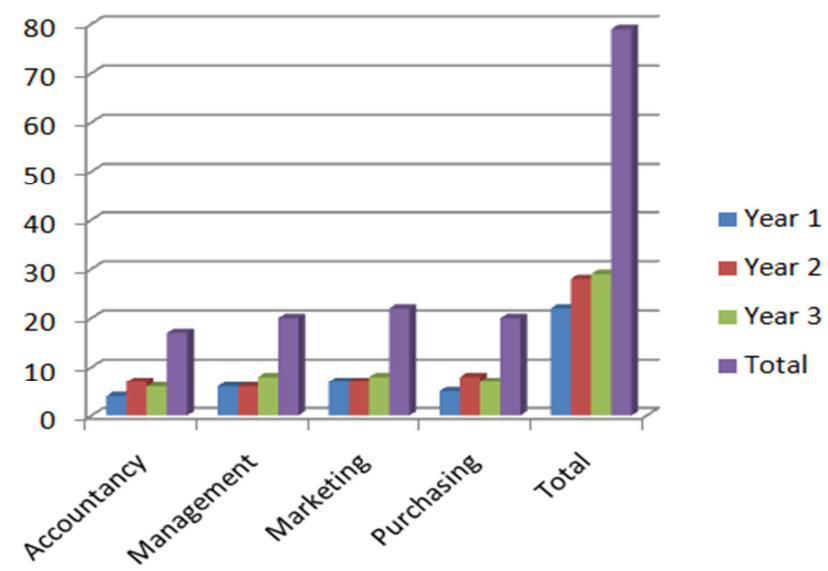

Figure 2. A pictorial representation of results across departments and year groups.

It is noteworthy that the results of the study corroborate the findings of Popken (1987). In Popken's study, he found out that $78 \%$ of the paragraphs contained topic sentences. The difference, however, between the two studies is that while the present study examines subjects' paragraph writing skills, in terms of the topic sentence and its subsequent development, Popken's focus (across disciplines) was whether or notthe topic sentence was employed in writing. It was also to challenge Braddock's (1974) crusade against the role of the topic sentence in paragraph construction. Similarly, while the 
results correspond well with Smith's (2008) findings that 95\% leave it there.

of discourse block units contain topic sentences, they do not support the findings of Braddock's study that only $13 \%$ of paragraphs of expository writing make use of topic sentences. We cannot but be on the same wavelength with Smith (2008) that "Braddock's finding, that only $13 \%$ of paragraphs in expository academicwriting begin with topic sentences, is misleading" (p.89).

The following examples from Mgt.Y 2:2 and Acc Y3.3 illustrate how the paragraph analysis was done. The paragraphs are presented unedited.

- ${ }^{1}$ Firstly, a person's sensory impressions can be affected by learning. ${ }^{2}$ Learning new ideas and behaviours impedes a person's state of sensing and is convinced to judge someone about his behaviour. ${ }^{3}$ For instance, a customer goes to buy a product from a company and after returning home the product as not functioning. ${ }^{4} \mathrm{He}$ then sends it back to the company only to be insulted and droven away, since he had already experience such uncustomerly care his perception towards that company will change forever. ( 82 words)

The structure of the paragraph above is as follows.

Sentence 1 Topic Sentence

Sentence 2 Major Support

Sentence 3 Minor support

Sentence 4 Minor Support

The interpretation is that Sentence 1 being the topic sentence of the paragraph embodies the topic or controlling idea. This topic sentence is a complex one as postulated by Juzwiak (2009), Gogovi et al. (2004) and Sekyi-Baidoo (2003). It is because it states the topic, "sensory impressions", and the sub-idea, "learning". Sentence 2 then picks up the sub-idea and makes a statement about it; hence it is a major support sentence. Sentences 3 and 4 are minor support sentences because they explain the idea in the major support sentence by providing an example in the form of a hypothetical episode.

- ${ }^{1}$ Integrity is one of the major responsibilities governing the Auditor's professional responsibilities. ${ }^{2}$ The auditor must be straight forward, justice and honest over issues concerning the company so that there will be no loss or risk occurrence. ${ }^{3}$ For example; if the auditor does not respect his integrity and go with face issues to govern the company is may mislead the company to take lose and risk. (65 words)

Acc Y3.3

Paragraph " $\mathrm{B}$ " is organized as follows

Sentence 1 Topic Sentence

Sentence 2 Major Support

Sentence 3 Minor Support

Similarly, in "B" the topic sentence is developed through the support sentences.

A closer examination of the two paragraphs shows that both follow paragraph organization principles employed by most writers. However, the shortness of the paragraphs shows lack of adequate development or completeness in terms of ideas; but since that is not the focus of the study we

\section{Implications}

The results of the present study have far-reaching implications for teaching essay writing in tertiary institutions, especially the polytechnics. There seems to be a mistaken belief among some polytechnic teachers that in so far as polytechnics focus mainly on vocational and technical education, the teaching of writing skills, of which paragraph construction is one, should take backstage. For this reason a lot of polytechnic students are not interested in English especially when they are informed by former students that their jobs will not entail the use of Basic English, but their specialty (Li 2012). Such reasoning crushes under the weight of demands made on the students by academic writing.

It is therefore imperative for polytechnics to strengthen departments responsible for teaching communication skills and other language related courses to enable them to effectively equip students with the needed paragraph skills for them to improve their academic writing.

Furthermore, the finding of the study is a wake-up call for researchers to also turn attention to polytechnic writing. The seemingly fondness for research into university writing is imperceptibly creating a gap in scholarship in polytechnic writing. Being stakeholders in the academic enterprise, the polytechnics offer fertile grounds for linguistic investigations. Turning our backs to research in the writing skills of polytechnic students will prove disastrous in the sense that their dissertations and otherwrite-ups may be couched in writing styles that will call into question academic writing in our tertiary institutions, especially polytechnics. It is hoped that this study will stimulate further research into the writing skills not only of the polytechnic students, but also students from the universities and colleges of education.

\section{Conclusion}

This study sought to find out the extent of polytechnic students' knowledge about paragraph development skills. The study area was Kumasi Polytechnic, Ghana, where a corpus of 120examination essays from four academic departments was analysed using Bainish paragraph prescription as the benchmark. The study showed that 79 essays representing $66 \%$ conformed to Bainish paragraph principles: a definite topic sentence followed by support sentences while 41 essays representing $34 \%$ had problems with paragraph development. The conclusion drawn from the results is that polytechnic students have a fair idea of structuring a paragraph.

On departmental basis, the study revealed that Marketing students had the largest number of essays (73.3\%) with definite paragraph structure while students from Accountancy recorded the least number $(56.6 \%)$. As regards year groups the results showed that final-year students (third year) had more essays $(72.5 \%)$ with well-developed paragraphs with the first-year group recording the least $(55 \%)$.

With the $41(34 \%)$ found not to conform to paragraph 
principles, the following findings were also made. Paragraph blocks or indentions were created with careless abandon giving rise to one-sentence paragraphs, some as short as two or three lines. In addition line, spacing (one or two) was used as paragraph boundaries instead of the conventional indentation breaking down various paragraphs into scores of discrete discourse blocks

Again,some paragraphs lack unity and coherence as a result of disjointed sentences which impeded a smooth and logical flow of ideas. The study also found out that quite a number of the essays did not have introductory paragraphs, which contained thesis statements from which topic sentences could be derived to build body paragraphs

Putting the findings together, one can conclude that the standard of paragraph skills among polytechnic students can best be described as above average: neither very good nor bad.This calls for the inculcation of rigorous paragraph writing instructions among polytechnic students. But in doing so we must teach them not to merely look at paragraphs "as isolated entities which follow rigid standards, but as units which function in relation to paragraphs which precede and follow them" (Smith 2008:92).

\section{Appendix}

Some sample paragraphs. The paragraphs are presented unedited.

1. Furthermore a promoter must always disclose what goes on in the company to the shareholders, Board of directors and other workers. He shouldn't keep to himself anything that borders him or her, but must always feel free to bring it on board to his members or head of the company. Also, he should not make secret profit, that is all profits gain by him should be stated by him to the Board Directors and the company at large He must also care for the properties or if the company is in need of furniture, land and so on he must be able to provide them for the company.

\section{Mgt Y3.4}

2. MTN communicates with its customer in order to differentiate the organizations products from its competitors in the market. They try to differentiate their product in a sense to be unique in the market. With differentiation, the brand image of MTN is unique in the sense of their colour yellow. And also the mobile money introduced by them in the first place. With the mobile money many people will switch to them and this is due to how they have differentiated themselves in the telecommunication market.

Mkt Y3.1

3. First of all, I will try to convince my management about the benefits we will get when we go international. To gain more profit when we go international. This will help us open up more branches and get foreign customers as well as profits in retain. It will help us to also gain more income because of the more customers we have outside the country.

\section{Pur Y3:3}

4. The following is a full essay with 5 paragraphs (presented unedited)

In decision making, certain measures must be consider to make, when and where to make rightful decision about a specific problem. These steps or process are as follows:

Firstly, Identification of the problem, In decision making, one must identify the kind of problem at hand, that is when the problem stated, what brought about the problem and how the issue is going to end wheather good or bad, one must identify the problem.

Also, Analysis, in making rightful decision, the person must analysis the problem. Analysis of a problem will enable an Individual to know the outcome of that issue or problem to identify what to do.

Again, Collection of Information or data. Whenever rightful decision is being made, one shoul collect Information or data from a reliable source. That is, Information that will enable you to have or get specific resource of the problem.

Moreover, development of alternative, to make good and reliable decision, one must develop certain alternatives to enable him or her to identify how the results are going to be like or when it will be and what is going to be the benefit of the outcme.

Mgt. Y1: 2

\section{References}

[1] Abubakar, H.A. (2014), Challenges of Globalization in Teaching of English of Use of English in Nigerian Polytechnics, IOSR Journal of Humanities and social Science, Vol. 19, Issue II, 23-27.

[2] Adika, G.S.K (1999), An Analysis of University Students' Expository Discourse, Unpublished Ph D Dissertation, University of Ghana.

[3] Afful, J.B.A. (2005), A Rhetorical Analysis of Examination Essays in Three Disciplines: The Case of Ghanaian Undergraduate Students, Unpublished Ph D Thesis, National University of Singapore.

[4] Alred, G. J. et al. (2012), The Business Writer's Handbook, $10^{\text {th }}$ ed. Bedford: St. Martins.

[5] Angus, J. (1862), Handbook of the English Tongue, London: Religious Tract Society.

[6] Anyidoho, L.A. (2002), Analysis of the Writing of Final Year University Students, Ghanaian Journal of English Studies, 1. 58-72.

[7] Bain, A. (1886), English Composition and Rhetoric, New York: Appleton.

[8] Ballard, B. and Clanchy, J. (1998), "Literacy in the University: Anthropological Approach. In G.Taylor, S. West and P. Nightingale (eds), Literacy by Degrees, Oxford: Milton Keyness, Oxford University Press. 
[9] Bond, S. J. \& Hayes J.R. (1984), "Cues people use to paragraph text", Research in the Teaching of English, 18, 147167.

[10] Bowman, D. (2009), "The One-Sentence Paragraph," Retrieved on 15 July 2014 fromezinearticles.com/?The OneSentence-Paragraph \&id=2055870.

[11] Braddock (1974), "The Frequency and Placement of Topic Sentences in Expository Prose," Research in the Teaching of English, 8, 287-302.

[12] Brown, G. \& Yule G. (1986), Discourse Analysis, Cambridge, Cambridge University Press.

[13] Bunton, D. (2005), The Structure of $\mathrm{Ph} \mathrm{D}$ Conclusion Chapters, Journal of English for Academic Purposes (3) 207224

[14] Chan, P.K. (1994) coherence in the Writing of Engineering Undergraduates in Singapore, Unpublished MA Dissertation, National University of Singapore.

[15] D'Angelo, F. J. (1986), 'The Topic Sentence Revisited", College Composition and Communication, Vol. 37, N0 4.

[16] Duncan, M. (2007), "Whatever Happened to the Paragraph?" College English, 470-475.

[17] Edwin, L. H. (2006), History of the English Paragraph Retrieved June 30, 2012 fromhttp://archieve.org/details/historyof english00lewirich.

[18] Gogovi, G.A.K. et al. (2004) Communicative Skills, Cape Coast, University Printing Press.

[19] Hinds, J.(1977), "Paragraph Structure and Pronominalisation" Papers in Linguistics, Vol. 10,Issue 1-2.

[20] Grimes, J. (1975), The Thread of Discourse, Mouton, The Hague Juzwiak, K. (2009), Stepping Stones: A Guided Approach to Writing Sentences and Paragraphs, New York, St. Martins.

[21] Lee, J.A.(1998), Substance, Style and Strategy, Oxford University Press.

[22] Li, H. (2012) "Research of Workplace English Teaching Model in Polytechnic College", International Conference on Economic Management and Engineering Technology, Lecture Notes in Information Technology, Vol. 18.

[23] Nichol, M. (2008), "How long should a paragraph be?" $\begin{array}{lllll}\text { Retrieved on } & \text { July } & 15 & 2014\end{array}$ fromwww.dailywritingtips.com/how-long-should-aparagraph.be/.

[24] Njoku, M.C. (1977), The Paragraph, In Oluikpe. B.O.A (Ed.) The Use of English for Higher Education, Onitsha, AfricanaFep Publishers Ltd. 209-230.

[25] Pardede, P (2012), "Major Supporting Sentence", Retrieved Jul. $\quad 10, \quad 2014$ frommyreadwriteboosterwordpress.com/category/languageskills/writing/paragraph-writing/page/2.

[26] Popken, R. L. (1987), “A Study of Topic Sentence Use in Academic Writing”, Written Communication, 4 (2), 209-228.

[27] Rasheed, S. A. et. Al. (2013), Paragraph Inner Structure: The Step Model, International Journal of Humanities and Social Science, Vol. 3, N0 12, 165-172.

[28] Rodgers, P. C. (1965), "Alexander Bain and the Rise of the Organic Paragraph.” Quarterly of Speech 51 ,399-408.

[29] Santhi, G. (2011), problems of teaching English in mixed ability classroom at polytechnic levelin India, IETEC Conference paper, Kuala Lumpur, Malaysia.

[30] Sekyi-Baidoo, Y. (2003), Learning and Communicating (2 ${ }^{\text {nd }}$ ed.), Accra, Infinity Graphics Ltd.

[31] Shaojun, J. (2008), "What do paragraph divisions indicate in narrative text?" Journal of Pragmatics, 29: 57-74.

[32] Shearer, N. A. (2009), "Alexander Bain and the Genesis of Paragraph Theory” DOI:1080/00335637209383139, Retrieved July 4, 2014.

[33] Smith, C. (2008), "Braddock Revisited: The Frequency and Placement of Topic Sentence in Academic Writing", The Reading Matrix Vol. 8, N0 1.

[34] Sporleder, C. \& Lapata M. (2004) "Automatic Paragraph Identification: A Study across Languages and Domains" Conference Paper, Empirical Methods in Natural Language Processing, Barcelona, 25 - 26 July.

[35] Stark, H.A. (1988), "What do paragraph markings do?" Discourse Processes, 11, 275-303.

[36] Warriner, J.E.(1982), English Grammar and Composition, New York, HBJ Publishers Webster's Universal Dictionary and Thesaurus (2003).

[37] Wilson, D. (1998), Discourse, coherence and relevance: A reply to Rachel Giora, Journal of Pragmatics, 29, 57-74. 